\title{
Explorando categorías
}

\author{
El género en el análisis \\ integral del proceso de recepción televisiva
}

AIMEE Vega MONTIEL*

Resumen. El objetivo del presente trabajo es reflexionar en torno a las posibilidades de incorporar la categoria de género al análisis de los procesos comunicativos y, en particular, de uno muy concreto: el proceso integral de recepción televisiva (Vega, 2004), en el caso específico del grupo de mujeres de las amas de casa. El supuesto central del que se parte es que la identidad de género determina las formas particulares en las que los sujetos se relacionan con la realidad social y, en concreto, con los mensajes mediáticos. Los argumentos de esta propuesta se apoyan en algunas de las aportaciones derivadas de una investigación empirica llevada a cabo entre amas de casa mexicanas, en el contexto de las elecciones presidenciales de 2000, con base en entrevistas en profundidad y en grupos de discusión.

\section{Introducción}

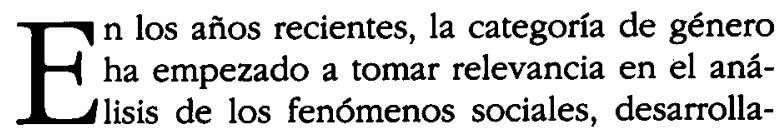
dos desde diversas disciplinas. Rescatar las relaciones, actividades y experiencias sociales del "ser mujer" o del "ser hombre" como eje clave para entender la forma en la que se construyen los procesos sociohistóricos, ha denotado las posibilidades de la perspectiva de género para elaborar una crítica transformadora y abrir nuevos debates y líneas de investigación.

\footnotetext{
- Especialista en comunicación política, cultura política, análisis de recepción, perspectivas de género y teorías y metodologías de investigación y comunicación. Facultad de Ciencias Políticas y Sociales de la UNAM, Instituto Tecnologico y de Estudios superiores de Monterrey, Campus Estado de México. Correo electrónico: aimeevegamx@yahoo. com.mx
} 
Es pertinente reconocer que en el campo de la comunicación, las reflexiones que incorporan la categoria de género apenas se han desarrollado. Acorde con otras disciplinas sociales, los trabajos respecto al origen y validez del conocimiento han relegado la experiencia de los sujetos desde su situación de género. Incorporarla, posibilitaría la reformulación de fundamentos clave de nuestra disciplina (como ha sucedido en el caso de la Sociología, de la Antropología y de la propia Ciencia Política), al tiempo que puede resultar esclarecedora en el análisis de los fenómenos comunicativos.

En ese tenor, el objetivo del presente trabajo es reflexionar en torno a las posibilidades de incorporar la categoría de género al análisis de los procesos comunicativos y, en particular, de uno muy concreto, el que denomino como el proceso integral de recepción televisiva (Vega, 2004), en el caso específico del grupo de mujeres de las amas de casa. El supuesto central del que parto es que la identidad de género determina las formas particulares en las que los sujetos se relacionan con la realidad social y con los otros, formas que pasan por la manera en la que se conciben como ciudadanos, en la percepción que tienen de las esferas doméstica y pública y en cómo las vivencian, en cómo participan en los procesos comunicativos y, en ese sentido, en cómo se relacionan con los medios de comunicación (concretamente, con la televisión) y en cómo interpretan los mensajes mediáticos.

De esa forma, en la primera parte ubicaré conceptualmente este objeto de estudio. Se elaborará una definición del proceso de recepción televisiva que servirá como punto de partida para la presentación de un modelo metodológico que he desarrollado para el análisis integral de este fenómeno, mismo que comprende tres niveles, uno de los cuales (el individual) es el que contiene la categoría que aquí me ocupa. También, explicaré la forma en la que se construye la identidad de género desde la experiencia de las amas de casa. En la segunda parte, se anotarán algunas evidencias de la importancia de incluir esta categoría, a partir de las aportaciones derivảdas de una investigación empírica llevada a cabo entre amas de casa mexicanas, en el contexto de las elecciones presidenciales de 2000 .

\section{Del marco teórico-conceptual}

\section{El proceso de recepción televisiva: hacia una definición}

Desde la perspectiva de los estudios de recepción -desarrollada por los estudios culturales y el análisis crítico de la recepción (Orozco, 1996; Lull, 1990; Jensen, 1987; Morley, 1980; 1986) - sabemos que, lejos de ser la mera representación de una relación causa (mensajes)-efecto (audiencia) 
(punto de vista planteado por la corriente de los efectos) este fenómeno comunicativo resulta un proceso de producción social de significado de los textos que es llevado a cabo por los miembros de la audiencia, proceso en el que tiene una importancia clave el contexto en donde se construye el significado.

Sin embargo, aunque se trata de un proceso que opera principalmente a escala micro, es pertinente reconocer que la recepción televisiva no es un fenómeno que se explique sólo en términos de la acción de los sujetos en sus contextos específicos, sino en tanto un proceso de transformación estructural, que si bien se visibiliza a través de las acciones de los receptores, se encuentra en diálogo permanente con el contexto espacial y temporal en el que se integran las dimensiones micro y macrosociales. Así, en el proceso de recepción televisiva lo micro implica reconocer y analizar teórica y metodológicamente, la actividad de la audiencia, y lo macro, la forma en la que esta actividad se articula con un tipo de discurso social (Lull, 1990).

De esa manera, al ser conceptuado como un fenómeno sociohistörico que se manifiesta en las escalas micro y macro, al proceso de recepción televisiva se le puede reconocer afectado por distintos elementos o mediaciones (Martín Barbero, 1990; Orozco, 1996). Unos, relacionados directamente con las formas en las que el discurso televisivo determina la manera en la que será interpretado por los receptores. Y otros, constituidos por una serie de factores que tienen que ver con la situación particular de cada sujeto: su nivel socioeconómico, el educativo, la edad y el género, así como por su conocimiento e interés sobre temas específicos y por las construcciones temáticas a través de las cuales establece conexiones entre su mundo cotidiano y el mundo presentado por los medios de comunicación (Jensen, 1998). También, por sus motivaciones, estrategias y hábitos de recepción (Martín Barbero, 1990; Orozco, 1996), y por lo que ha sido denominado como las comunidades de interpretación (Jensen, 1987; Morley, 1980), espacios físicos y simbólicos en los que el receptor construye el sentido de los mensajes mediáticos (como la familia, la escuela y el trabajo), comunidades en las que los líderes de opinión desempeñan un papel determinante en la interpretación que los sujetos hacen de la realidad social.

Si se toma como base esas claves, el proceso de recepción televisiva se puede definir como:

- Un acto social, porque es en la realidad social en donde se manifiesta,

- un proceso activo y en movimiento, porque es cognitivo y reflexivo, en tanto que es un acto de producción de significado en el que participan los receptores y la propia televisión como productora de contenidos, discursos y cogniciones, y 
- un diálogo, en tanto que receptores y televisión mantienen una interacción permanente, de ida y vuelta, de objetivos, informaciones, contenidos e intereses, que rebasa el límite espacio-temporal del acto de mirar televisión.

Definido de esa manera, como un fenómeno social, activo y dialógico, considero que el proceso de recepción televisiva requiere de un análisis integral que observe, por un lado, la forma en la que las audiencias interpretan y se apropian de los mensajes televisivos, pero, al mismo tiempo, los contenidos televisivos y el propio papel de ese medio de comunicación, en tanto que se trata de una institución que forma parte de una estructura económica y política bien definida y que juega un importante papel, en cuanto productora de discursos, en la conformación de las audiencias como sujetos sociales.

Mirar la recepción televisiva como un proceso social complejo, que se manifiesta a nivel macro y micro y que involucra la participación de, por lo menos, dos actores centrales, lleva a asumir que no es posible construir una forma unívoca de analizarlo. Más bien, sugiere proponer un modelo metodológico que permita entender cuáles son los elementos que median este proceso y la importancia de cada uno. Partiendo de esta premisa, considero que un estudio integral del proceso de recepción televisiva implica tres dimensiones básicas de observación: una individual, una televisiva y una social-institucional (el modelo se desarrolla en el cuadro 1):

1. La dimensión individual hace alusión a los receptores; es decir, a los sujetos concretos (en este caso, a las mujeres amas de casa). La encuentro asociada a los factores que vuelven a cada sujeto único, que le determinan una identidad particular y que lo ubican en realidades concretas. Estos elementos inciden en la forma en la que dará un significado concreto a los mensajes televisivos. Esta dimensión se divide a su vez en dos escalas básicas: una que he denominado estructural y que alude, por una parte, a los elementos que le determinan una identidad específica al sujeto: la edad, el nivel escolar y la ubicación en la esfera socioeconómica $y$, por la otra, a los factores sociohistóricos que le definen su identidad de género. La otra escala que corresponde a esta dimensión es la perceptiva, que se refiere a los esquemas cognitivos del receptor. Esta escala implica los conocimientos del receptor en este proceso, así como sus intereses y opiniones y sus expectativas, anhelos y deseos.

2. La dimensión televisiva se refiere al papel de la televisión como 
visibilizadora de los actores y de las discusiones, opiniones e interpretaciones pertenecientes a la esfera pública y como fuente clave en la construcción de conocimiento que sobre esta realidad hacen los sujetos. Esta dimensión implica una escala formal, que se refiere al análisis de los discursos televisivos. $Y$ comprende también una escala interpretativa, que comporta analizar la interpretación que de esos mensajes hacen los sujetos.

La dimensión social-institucional se refiere a reconocer que el sujeto es un participante activo en diversas instituciones sociales al mismo tiempo: la familia, la escuela, el trabajo, las asociaciones civiles, los partidos políticos, etcétera. Se entiende que estos escenarios son contextos que proveen al sujeto de elementos (conocimientos, definiciones e interpretaciones) que le ayudan a producir un significado de los mensajes televisivos. Esta dimensión comprende una escala social.

CUADRO 1. Modelo para el análisis integral del proceso de recepción televisiva

\begin{tabular}{lll}
\hline Dimensión & Escala & Categorias \\
\hline Individual & $\begin{array}{l}\text { De referencia } \\
\text { Perceptiva }\end{array}$ & $\begin{array}{l}\text { Género/edad/escolaridad/ } \\
\text { Posición socioeconómica } \\
\text { Cognitiva/afectiva/valorativa/subjetiva }\end{array}$ \\
Televisiva & $\begin{array}{l}\text { Formal } \\
\text { Interpretativa }\end{array}$ & $\begin{array}{l}\text { Posicionamiento de los receptores } \\
\text { Construcción de la realidad } \\
\text { Elección-consumo }\end{array}$ \\
& $\begin{array}{l}\text { Prácticas de comunicación y hábitos } \\
\text { de recepción } \\
\text { Construcción de significado }\end{array}$ \\
Social- & Social & $\begin{array}{l}\text { Comunidades interpretativas } \\
\text { Líderes de opinión }\end{array}$ \\
\hline
\end{tabular}

Fuente: Elaboración propia.

La categoría de género

Dentro de las categorías que se observan en el "Modelo para el análisis integral de la recepción televisiva", es sobre la de género que se centró mi interés en el presente artículo.

Como perspectiva, el género es una línea de análisis que permite observar que detrás de las diferencias sexuales entre "ser mujer" y "ser hombre" se han construido desigualdades sociales, políticas, económicas y culturales que han marginado a las mujeres de la esfera pública.

La perspectiva de género abre la posibilidad de entender la formación de la identidad como producto de un largo proceso que se va construyendo desde que se espera el nacimiento de una hija o un hijo. Se inicia con 
discursos y con acciones sociales sobre cómo se nombra y lo que se espera de las personas. Este horizonte cultural es el que abre o cierra ciertas posibilidades de vida para las mujeres y los hombres, es decir, los mandatos.

Así, el primer mandato central de lo que es ser hombre es el de ser jefe de familia; es decir, asumir la responsabilidad de trabajar para mantener y guiar.

Para la mujer, el primer mandato es el de asumir el papel de madre y esposa. Éstos, son los ejes que constituyen, real y/o simbólicamente, el ser mujer en nuestra sociedad, su deber ser: casarse, tener hijos, cuidar de los otros: "Estos elementos se trazan como hechos incuestionables en cumplimiento de sus atributos sexuales, como eje social y cultural de su feminidad" (Lagarde, 1990: 107).

Ese deber ser se encuentra determinado por su pertenencia a la esfera doméstica, ámbito en el que la mujer tiene la tarea de realizar todas y cada una de las actividades destinadas a la reproducción de la fuerza de trabajo, a la satisfacción de necesidades de primer orden de los otros. Pero no sólo eso, su trabajo abarca aspectos esenciales de la existencia global de los sujetos: sus formas particulares de relacionarse con el mundo, de hacer, de sentir, de estar, sus creencias, saberes y lenguajes (Lagarde, 1990).

En el caso concreto de las amas de casa, esos mandatos se hacen más evidentes, pues son los que las haven visibles/invisibles ante los otros. Este deber ser se materializa a través de tres factores fundamentales: la reproducción, el espacio y el trabajo.

La reproducción biológica, es decir, su naturaleza, se detecta como el primer elemento que traza la identidad genérica de esas mujeres. Representa la principal y máxima justificación para que sean ellas quienes se responsabilicen de los otros. El ser procreadoras les confiere una serie de responsabilidades a las que no pueden renunciar: nutrir, cuidar, ser testigo y vigía de sus vidas. La nutrición y el cuidado de los otros, al lado de la reproducción, han sido relegados al ámbito de la naturaleza y excluidos de toda consideración pública.

El espacio doméstico se constituye como la segunda fuente de identidad de las amas de casa. La casa es su espacio vital, exclusivo, del que no deben apartarse para no dejar de cumplir con su deber ser, el de madres y esposas. Así, la esfera doméstica constituye también un espacio de reproducción ideológica para ellas, en tanto que es ahí en donde se define y se interioriza lo que es ser mujer, en términos de la división sexual del trabajo y de la construcción sociohistórica de género.

En tercer lugar, el trabajo doméstico, definido como inactividad en tanto que engloba el conjunto de actividades privadas, individuales y concretas, que se realizan en la esfera doméstica, y que se encuentran destinadas a la satisfacción de las necesidades de la familia -lo que les 
asigna el carácter de gratuito y obligatorio-, es el tercer elemento que determina la identidad de esas mujeres.

Y puesto que son asignados "por naturaleza" o "por obligación", esos tres factores dan un carácter fundamental a la identidad de las mujeres amas de casa: la invisibilidad. Dado que su función biológica, su espacio y su trabajo lo materializan en los otros, teniendo como marco el ámbito doméstico (el que nunca se ha destacado por ser un generador de opiniones individuales), todo lo aquello que se considera como parte de esta esfera -incluidas las amas de casa - es definido como extraño y ajeno al mundo público de la ciudadanía, lo que deriva en una posición deficitaria de esas mujeres en la esfera pública-política.

Y será esta construcción social de lo que es ser una ama de casa, lo que definirá a esas mujeres la manera en lá que se relacionen con la realidad social: con la esfera doméstica, con la esfera pública $\mathrm{y}$, con el tema de análisis que aquí me ocupa; la forma en la que se relacionan con los medios de comunicación y, concretamente, con los mensajes televisivos.

Revisemos, pues, algunas evidencias de las posibilidades que representa incluir esta categoría en el análisis empírico del proceso integral de recepción televisiva.

\section{De las evidencias empiricas}

(o de por qué incluir la categoría de género)

\section{Apuntes metodológicos}

Las evidencias que a continuación se discuten, derivan de un trabajo empírico desarrollado en el marco del proceso electoral de $2000 .^{1} \mathrm{El}$ objetivo que lo guió, fue el de analizar la relación entre la recepción de noticias sobre las elecciones emitidas por los telediarios mexicanos y la decisión de voto de las amas de casa. La pregunta eje de la investigación, fue: ¿De qué manera el acto de mirar telediarios contribuye a que las amas de casa: $a$ ) conozcan y entiendan un proceso político, b) decidan su voto, y c) conciban sus acciones, identidad y participación política?

La estrategia metodológica, consideró trabajar con amas de casa residentes en el Distrito Federal y el área metropolitana, con rangos de edad entre los 25 y los 60 años, de los tres sectores socioeconómicos básicos (alto, medio y bajo) y con estudios que fueran del nivel de primaria al superior. Las dos herramientas que utilicé fueron los grupos de discusión y las entrevistas en profundidad. El desarrollo de las sesiones con los grupos y

\footnotetext{
' Este trabajo forma parte de la tesis doctoral de la autora, titulada La decisión de voto de las amas de casa mexicanas y las noticias electorales televisadas (2004).
} 
con las entrevistas tuvo lugar en los días previos a las elecciones, con el objetivo de conocer la percepción de las informantes sobre diversos temas.

En las siguientes líneas se discutirán algunos hallazgos en torno al papel que desempeña la identidad de género en el proceso de recepción de esos mensajes, entre las amas de casa. Para tal propósito, me centraré en la exposición de los siguientes temas: fuentes de información, motivación para mirar los telediarios, contexto y hábitos de recepción, comunidades de interpretación y líderes de opinión. La finalidad es descubrir la importancia de incluir esta categoría en el análisis de los procesos comunicativos.

\section{Los ballazgos}

De sus fuentes de información

En el momento en el que se realizó este trabajo empírico, todas las participantes afirmaron estar interesadas en las elecciones, razón por la cual procuraban mantenerse informadas del proceso electoral a través de distintas fuentes, teniendo como la principal los medios de comunicación.

Varias de estas mujeres, sin distinción de estrato socioeconómico, dijeron sintonizar algún noticiario de radio. El preferido por la mayoría fue "Monitor", conducido por José Gutiérrez Vivó, periodista que fue reconocido por las propias amas de casa como un líder de opinión. Su preferencia por los informativos de radio encuentra razón en que les representa más credibilidad que otros medios.

En algunos casos, y particularmente en el de las amas de casa que tienen una carga de trabajo doméstico importante, escuchar los noticiarios de radio les representa una ventaja porque no les demanda una recepción exclusiva. Pueden hacerlo al tiempo que limpian la casa o mientras conducen el auto de camino a la escuela de sus hijos:

Yo oigo muchísimo el de radio porque estás haciendo tus cosas, porque estás oyendo y haciendo otras cosas. Lo oigo en la casa o en el coche, siempre que voy por ellos a la escuela,

La prensa es otro recurso de información para las participantes. Aunque su consumo es en extremo marginal, no encuentra distinción entre los niveles socioeconómicos: tanto mujeres del medio, como del bajo y del alto, tienen en este medio una fuente de información sobre las elecciones. El diario Reforma es el más leído entre ellas, aunque mantienen una posición crítica frente a los contenidos de este diario porque lo consideran tendencioso. Piensan que favorece al gobierno.

Hay que apuntar que la elección de estos diarios no depende exclusi- 
vamente de ellas. En algunos casos, estas mujeres leen un periódico determinado porque es el que llevan a casa sus hijos o, las más de las veces, su marido:

Pues leemos Reforma, a veces El Financiero, pues es según el que traiga mi esposo, no tiene fijo. Antes leía La Jornada, pero dice que ahora ya no le gusta.

De todos los medios de comunicación, el que se erige como la principal fuente de información sobre los comicios para este grupo de recepción es la televisión. La mayoría de las amas de casa, del nivel medio, bajo y alto, afirmaron tenerla como la vía principal para informarse de las campañas presidenciales. ¿Por qué privilegiar a este medio? por su inmediatez: es más fácil enterarse de las campañas presidenciales a través de la televisión.

Para las amas de casa de más bajos ingresos y para algunas del medio, la televisión representó su único recurso de información sobre las elecciones. Tanto en los grupos como en las entrevistas, fue posible percibir que mucho del conocimiento que las dotó de argumentos para opinar sobre estos comicios se encontraba fundamentado en lo que habían visto en la televisión.

De todos los formatos, fueron los telediarios los programas más atendidos por las amas de casa. Dijeron mirarlos con regularidad. La mayoría de ellas, a diario. De todas las emisiones, los nocturnos resultaron los más vistos por estas mujeres: "Noticiero", "Hechos", "Noticias" y "CNI Noticias". De ellos, son el de Televisa y el de TV Azteca los más vistos por estas amas de casa, sin distinción de edades o nivel socioeconómico. "Noticias", de Canal 11, encuentra una audiencia marginal, aunque sí identifican a esta televisora como una productora de buenos contenidos, educativos y culturales. Es visto por las amas de casa de los estratos medio y alto. Al final, se encuentra "CNI Noticias", de Canal 40. Sólo resultó ser visto por informantes que se ubican en el nivel socioeconómico bajo y en el medio.

Por otro lado, aun cuando constituyen la principal fuente de información, estos telediarios tienen un nivel muy bajo de credibilidad entre este grupo de audiencia. La mayoría de las participantes en esta investigación opina que en México es muy difícil que estos noticiarios logren cumplir con su función social porque se encuentran influidos por los intereses que los dueños de las empresas televisivas tienen con el gobierno y con algunos partidos. Subyace su escepticismo en torno a la veracidad de las noticias porque piensan que siempre tienen una tendencia. Además, critican el amarillismo y la espectacularización prevaleciente en las noticias que, de acuerdo a las discusiones sostenidas por estas mujeres, obedecen a la lógica comercial que guía hoy a las televisoras mexicanas. 
De sus motivos

La primera razón que motiva a todas estas amas de casa a mirar los telediarios es la de informarse. Lo consideran parte de un deber ser ciudadanúm. Hacen referencia a esta actividad como si se tratara de una obligación, como algo que se "tiene" que hacer: "Una debe estar enterada porque finalmente nos afecta".

Algunas mujeres del nivel socioeconómico alto, que también atienden otras fuentes, valoran la información que este medio les provee sobre lo que acontece en su país y en el mundo. Ver los noticiarios forma parte de su vida cotidiana:

Yo no me imagino apagar la tele a las 10:30 de la noche, cuando empieza el noticiario. No tendría ni idea ahorita de nada, ni de qué pasa en mi ciudad ni en el país.

En el contexto de estas elecciones, las mujeres más jóvenes pertenecientes a la clase alta, consideran que los telediarios son el principal medio que les ha posibilitado conocer, aunque sea de manera superficial, cómo van las campañas, y ello les ha dado la pauta para revisar otras fuentes:

Si ya ves que le están tirando mucho a uno [a un candidato], entonces vas y ves qué hizo de bueno.

Una cualidad que las participantes de los grupos de discusión y que mujeres pertenecientes al estrato alto destacan de estos programas, comparándolos con otras fuentes, es que les proporcionan la información de manera resumida. Consideran que es más fácil enterarse por los telediarios porque les permite obtener un panorama general de lo que ha sucedido a lo largo del día, sin que tengan que invertir mucho tiempo en ello. Algunas de estas mujeres valoran positivamente el resumen introductorio de estos programas de noticias porque les posibilita enterarse en muy pocos minutos de la información más importante.

Otra razón por la que dicen ver los telediarios es por costumbre. En ese sentido, la elección concreta de un telediario no ha dependido tanto de ellas como del hecho de que, mirarlo, forma parte de una tradición familiar. Entre las amas de casa más jóvenes y de escasos recursos, ese fue el principal argumento para explicar por qué miran un telediario: Yo siempre he visto el " 2 ", ora sí que desde muy pequeñita.

La compañía que a estas mujeres les representan los programas de noticias y, en general, la televisión, es otro de los elementos que valoran para mirarlos. Este fenómeno toma relevancia en el caso de las informantes que transcurren la mayor parte de su tiempo en el hogar: dado que 
pasan la mayor parte del día solas, a las mujeres de edad más avanzada que tienen hijos mayores, que ya están casados o que trabajan, la televisión les proporciona una compañía, las compensa, pues, afectivamente:

Yo tengo la televisión encendida todo el día, veo los noticiarios y las novelas, y cuando me subo a limpiar, prendo el radio.

Veo la tele y los noticiarios porque casi todo el día estoy sola.

En este tenor, como señala Janice Radway (1984), los medios de comunicación representan para muchas de estas mujeres un escape a la soledad que les significa vivir la mayor parte de su tiempo en el espacio doméstico, de ahí que frecuentemente encuentren en ellos al acompañante ideal a su jornada interminable de trabajo.

Por último, en el caso de las mujeres de escasos recursos, el locutor constituye una buena razón para mirar un telediario. La siguiente discusión, que tuvo lugar en uno de los grupos, sugiere pensar en la personalización del locutor como un fenómeno que toma relevancia:

M: Entonces, ¿qué les gusta?, ¿̇el conductor o el noticiario?

P: En el 2, el noticiario, porque aunque quiten a Joaquín, yo sigo ahí pórque tengo mucho tiempo viendo el 2.

M: ¿Y qué pasa con "Hechos"?, si quito a Javier ¿qué pasa?, ¿lo sigo?

P: ¡Ay, no! Se viene abajo.

P: A lo mejor no es todo el conductor, pero sí es indispensable, ¿no?

De acuerdo con Stam (1983) y con Buckingham (2000), el atractivo del presentador y su espontaneidad, constituye uno de los placeres esenciales de los que algunos programas de noticias proveen a sus espectadores. Este fenómeno tomó relevancia en la discusión celebrada en uno de los grupos. Seguramente fue la confianza y la complicidad que estas mujeres encontraron con las otras, lo que las motivó a "confesar" que, para ellas, una de las razones fundamentales por las que miran el telediario, es porque encuentran atractivo a su locutor:

M: ¿Es importante conocer al conductor?

P: Sí.

P: Sí, por ejemplo, Javier Alatorre tiene mucho porte.

P: Es importante que el conductor sea agradable, iverdad?, porque a mí la verdad Joaquín López Dóriga no me agrada.

P: ¡No!

P: No, se ve muy serio, muy seco, muy...

$P:$ Feo! [risas]

P: Javier Alatorre sí tiene más porte, más personalidad para dar noticias [risas]. Joaquín es bueno, pero es feo. 
M: A ver, entonces: ¿Joaquín es bueno, pero es feo?

P: Sí, y ya también está viejo [risas].

P: A mí de Alatorre me gusta mucho su voz.

$\mathrm{M}$ : ¿Y qué más les gusta de él?

P: Que es guapo también [risas].

De sus contextos y sus hábitos

Como lo señalan David Morley y Roger Silverstone (1991), el hogar, como el centro de la vida cotidiana de los sujetos, constituye el marco principal en el cual se desarrolla el acto de mirar televisión. Los hallazgos de este estudio así lo corroboran. Para todas las participantes, su casa es el primer escenario en donde la recepción de los telediarios toma forma.

Los espacios concretos dentro del hogar en los que las mujeres prefieren mirar estos programas, son diversos. La sala es el marco principal en el que todas estas amas de casa ven los noticiarios. De acuerdo con Morley (1986), es éste el escenario familiar más importante. Es el lugar de encuentro entre los miembros de la familia, en donde comparten y comentan su vida diaria. En esta socialización, la televisión forma parte fundamental. Su presencia en la sala de los hogares, se da, pues, por descontada.

Por otro lado, para la mayoría de estas amas de casa, la actividad de mirar los telediarios es esencialmente social porque suelen hacerlo acompañadas $e$ ir conversando sobre lo que van mirando, posibilidad que valoran como positiva. En este sentido, como lo han observado otros trabajos (Morley, 1986; Lull, 1990), es la familia el núcleo central entre la televisión y la vida cotidiana.

Para las participantes más jóvenes en esta investigación, el marido es su acompañante habitual pues a la hora en la que miran el telediario sus hijos pequeños ya están dormidos. Para las amas de casa de mayor edad, sus hijos adolescèntes forman parte del auditorio de estos programas dentro del hogar. Sin embargo, como se ha dicho, también hay participantes que los miran solas. En estos casos, es porque a la hora en la que empiezan los informativos todavía no arriban al hogar los otros miembros de la familia.

En lo relativo a sus hábitos de recepción, esta investigación evidencia la manera en la que se ven determinados por la situación particular de género de estas mujeres. La percepción que ellas tienen de su hogar como un lugar de trabajo y de responsabilidades continuas, propicia que su consumo de estos programas sea muy particular. Esta práctica se ve interrumpida constantemente por otras actividades, dado que para ellas el hogar no es primordialmente un lugar para el ocio (como sí lo es, usualmente, para su marido), sino un lugar de trabajo. 
De ese modo, se puede considerar que, en la mayoría de los casos, la recepción de los telediarios por parte de las mujeres de esta investigación, no es atenta, dado que hacen otras actividades al tiempo que miran los informativos. Actividades asociadas a su trabajo doméstico: planchar, cocinar o hacer la tarea con sus hijos. Este hallazgo incluye a todas las mujeres: desde las que no gozan de una situación económica privilegiada, atravesando por las de clase media, así como a las que pertenecen a los estratos más altos y que son quienes comúnmente cuentan con la ayuda de una empleada doméstica:

Cuando [mi esposo y yo] vemos el noticiario, al mismo tiempo hacemos otra cosa: él lee y yo hago algo de los niños.

Por último, las relaciones de poder son clave en los hábitos de recepción de estos programas entre este grupo de audiencia. Si partimos de que, en el seno de la sociedad, el poder pertenece a los hombres, este mismo orden se traslada al espacio doméstico.

En la mayoría de los casos, sin distinción por clase social o por edad, es el marido quien elige el noticiario que se mira en la casa. En segundo lugar, son los hijos varones. Después, son las hijas cuando son adoléscentes o jóvenes. Al final de la lista, son estas amas de casa quienes lo escogen. La explicación que encuentran a ello es porque reconocen que los otros tienen más conocimiento sobre los temas, lo que les da la autoridad para elegir qué noticiario mirar. Hay, un reconocimiento implícito de que ellos son los que saben y, por lo tanto, una desvaloración sobre los conocimientos propios.

$\mathrm{Y}$ aunque hay mujeres a quienes les molesta esta situación, de cualquier manera, terminan aceptándola:

En la noche, mi esposo llega y no me deja ver los noticiarios, por eso me puse a bordar, porque es un pleito con la tele. A mí me gusta ver "Hechos", a él le gusta ver a López Dóriga y a mí no me gusta. ¡Me choca!

El poder se hace aún más evidente en el caso de las televisiones con control remoto: casi ninguna de las informantes se "adueña" de él, es más bien característico que su posesión le corresponda al hombre:

Generalmente mi esposo tiene el control, pero no afecta. Le digo: "Ya cámbiale a tal".

La posibilidad que da el control remoto de hacer "zapping", es una actividad que disgusta a la mayoría de estas mujeres, porque constituye una práctica que ellas definen como masculina, que asocian a los hombres de la casa: 
estos líderes, porque les representan una fuente de información y de discusión fundamental para sus acciones políticas; pero, también, porque tienen una baja autoestima en torno a sus conocimientos, juicios y valoraciones acerca de esos temas, lo que propicia que tampoco reconozcan en otras mujeres una capacidad reflexiva y crítica.

De esa manera, se observa cómo es que las limitaciones ideológicoculturales van unidas a las creencias, valores y comportamientos que históricamente han incorporado y reproducido estas mujeres. Éstos se han ido construyendo sobre las bases del que domina el babitus de la cultura mexicana y que, según vemos, tiene una incidencia directa en la participación de estas mujeres. En conclusión, es su identidad la que define sus comunidades y sus líderes como espacios de socialización y de interpretación, pero también, en algunos casos, como barreras que les dificultan la construcción de una identidad política propia.

\section{Conclusiones}

Una vez que se ha presentado la propuesta y discutido los argumentos, la principal conclusión que se desprende de este trabajo es que la categoría de género comporta un lugar clave para el análisis de los procesos comunicativos.

Luego de observar la participación de las amas de casa en el proceso de recepción televisiva, lo que se ha constatado a lo largo de estas páginas es que la situación social de género de estas mujeres, es la que les determina formas concretas de entender la realidad social y de relacionarse con los mensajes mediáticos.

En primer lugar, este trabajo ha mostrado que, de todas las fuentes de información, la preferencia de este grupo de audiencia por los telediarios, encuentra una relación directa con el hecho de que sean amas de casa. Se ha observado de qué manera pertenecer al ámbito doméstico influye a todas estas mujeres en la elección que hacen de telediarios, de horarios y hasta de tipos de noticias. Ello explica que sintonicen preferentemente las emisiones nocturnas de estos programas porque es el momento en el que la carga de trabajo doméstico ha disminuido, een algunos casos, es la hora en la que sus hijos pequeños ya se encuentran descansando.

Su identidad también les determina lugares, hábitos y prácticas de recepción televisiva. De acuerdo a los testimonios recogidos, su recepción tiene lugar en el espacio al que estas mujeres se encuentran adscritas históricamente: el hogar. Y dentro de él, a lugares a los que se los asocia por naturaleza, como la sala. Así también, sus hábitos de recepción se ven acompañados, en todo momento, por las actividades que ellas desempeñan, propias de su trabajo doméstico: bordar, cocinar y limpiar. De la misma forma, las relaciones de poder, que hacen alusión a la dominación 
masculina de la que es objeto importante su condición de amas de casa, median de manera central sus hábitos de recepción - desde el hecho de que la selección de los telediarios que miran habitualmente no dependa de ellas, hasta del monopolio sobre el uso del control remoto-. Por último, su identidad se proyecta en la valoración positiva que hacen del acto de mirar televisión, por cuanto les representa la interrupción momentánea de la soledad en la que su condición las sumerge. Así también, en tanto les posibilita el encuentro con la familia.

Todo lo anterior, no se traduce en ningún momento en una recepción pasiva. Partiendo de que valoran la actividad de informarse como un deber ciudadano, todas las amas de casa que han participado en este estudio elaboran reflexiones críticas en torno a los acontecimientos; en primer lugar, a partir de los recursos que les proveen otras fuentes de información -que se hallan en la radio y en la prensa-, a partir también de la discusión de estos temas en los espacios en los que habitualmente socializan y que, en el caso de estas mujeres, ha presentado a la familia como el primordial y a partir de las figuras que ellas reconocen como líderes de opinión que, en su mayoría, halla como la principal al marido. $\mathrm{Y}$ primordialmente, a partir de su experiencia de vida concreta. Así, esta búsqueda permanente de fuentes de información y de interpretación denota la inquietud de estas mujeres por construirse como ciudadanas.

Es por eso que los hallazgos discutidos en este trabajo dan razones para considerar la categoría de género como una pieza clave en la reflexión en torno a los fenómenos comunicativos.

Por todo lo expuesto, es importante asumir el carácter de intervención que representa el trabajo que desarrollamos desde la universidad porque a través de él podamos darle voz a los sujetos que históricamente han sido relegados del espacio social. En ese sentido, si bien la presente investigación permitió conocer algunos aspectos de este fenómeno, considero que todavía son muchos los elementos de análisis por explorar. Por ello, sugiero como posibles líneas de investigación a continuar en el ámbito de nuestra disciplina:

- El análisis de los procesos de recepción televisiva de amas de casa en contraste con el de mujeres que viven experiencias de vida distintas, tanto en el ámbito doméstico como en el público (estudiantes, profesionistas, empleadas, obreras, etcétera).

- El análisis de estos procesos en comparación con los de colectivos masculinos (jefes de familia, estudiantes, profesionistas, empleados, obreros, etcétera), de manera que permitan tener una visión más amplia acerca del papel que desempeña la identidad de género en esos procesos. 
Si algo queda claro, es que los grupos de audiencia, constituidos por mujeres y por hombres con intereses bien diversos, participan de manera activa en los procesos sociohistóricos. Lo que se requiere, entonces, es que promovamos la apertura de espacios para que todas las formas de ser sujeto puedan ser reconocidas.

\section{Bibliografia}

Buckingham, D. (2000), The Making of Citizens. Young People, News and Politics, Routdlege, Londres.

Dahlgren, P. (1992), "Introduction", en P. Dahlgren y C. Sparks, (eds.), Journalism and Popular Culture, Sage, Londres.

- (1986), "Beyond information: TV news as cultural discourse", en Communications, 12, 2, pp. 125-136.

Jensen, K. (1995), The Social Semiotics of Mass Communication, Sage, Londres.

220 (1992a), "El análisis de la recepción: la comunicación de masas como producción social de significado", en $\mathrm{K}$. Jensen y $\mathrm{N}$. Jankowski (eds.), Metodologias cualitativas de investigación en comunicación de masas, Bosch, Barcelona, pp. 165-180.

- (1992b), "Erudición humanística como ciencia cualitativa: contribuciones a la investigación sobre la comunicación de masas", en K. Jensen y N. Jankowski (eds.), Metodologias cualitativas de investigación en comunicación de masas, Bosch, Barcelona, pp. 27-56.

- (1992c), "La política del multisignificado: noticias en la TV, conciencia cotidiana y acción política", Cuadernos del PROIICOM, núm. 4, Universidad Iberoamericana, México.

- (1987), "Qualitative Audience Research. Towards an Integrative Approach to Reception", en Critical Studies in Mass Communication, vol. 4, núm. 1, pp. 21-36.

Lull, J. (1992) "La estructuración de las audiencias masivas", en Diálogos de la Comunicación, núm. 32, (en línea), http://wwww.felafacs.org/revdialogos/ dialogos/pdf.32/lull.pdf (consulta, junio de 2001).

- (1990), Instde Family Viewing: Etnographic Research on Television's Audiences, Routledge, Londres.

- (1988), World Families Watch Television, Sage, Newbury Park.

(1980), "The Social Uses of Television", en Human Communication Research, vol. 6, núm. 3, pp. 195-209.

Martín Barbero, J. (1987), De los medios a las mediaciones, Gustavo Gili, México. Morley, D. (1996), Televisión, audiencias y estudios culturales, Amorrortu, Buenos Aires.

(1986), Family Television, Comedia/Routledge, Londres.

(1980), The 'Nationwide' Audience. Structure and Decoding, British Film Institute (BFI), Londres.

Orozco, G. (2001), "Audiencias, mediaciones y televisión pública. La deconstrucción múltiple de la televidencia en la era del avasallamiento mediático", en Televi- 
sión pública en América Latina: del consumidor al ciudadano, Fundación F. Ebert, Colombia (en prensa).

(1997a), "La televidencia de lo político: un complejo proceso de mediaciones, en Oficios Terrestres, núm. 4, Perú, pp. 18-21.

(1997b), La investigación en comunicación desde la perspectiva cualitativa, IMDEC, Guadalajara.

- (1996a), Televisión y audiencias: un enfoque cualitativo, Ediciones de la Torre, Madrid.

- (1996b), "Hay que hacer algo, pero no somos los indicados. Ámbitos de mediación y supertemas en la televidencia de las noticias", en Comunicación y Sociedad, núm. 27, mayo-agosto, Universidad de Guadalajara/DECs, Guadalajara, pp. 111-140.

- (1996c), "Amigas y enemigas. Madres mexicanas frente a la television", en Signo y Pensamiento, núm. 28, Universidad Javeriana, Bogotá, pp. 75-86.

(1993), "Dialéctica de la mediación televisiva: estructuración de estrategias de recepción por los televidentes", en Analisi, núm. 15, diciembre, Universidad Autónoma de Barcelona, Barcelona, pp. 31-44.

Stam, R. (1983), "Television news and its spectator", en E. Kaplan (ed.), Regarding Television, Frederick, MD, American Film Institute.

Vega, A. (2004), La decisión de voto de las amas de casa mexicanas y las noticias electorales televisadas. Tesis de Doctorado, Universidad Autónoma de.Barcelona, Barcelona, España.

- (2003), "Audiencias, urnas y pantallas en México", ponencia presentada en el Encuentro de la Asociación Mexicana de investigadores de la Comunicación, Puebla, México, junio.

- (2002) "La recepción de las noticias electorales televisadas entre las amas de casa mexicanas", ponencia presentada en el Congreso de la ALAC, Bolivia, junio. 